\title{
HOSPITAL PRIORITY SETTING IN A MIXED PUBLIC/PRIVATE HEALTH SYSTEM: A CASE STUDY OF A CHILEAN HOSPITAL
}

\author{
Carolina Valdebenito*, Lydia Kapiriri**, Douglas K. Martin***
}

\begin{abstract}
The purpose of this study was to describe, using qualitative case study methods, and evaluate, using the ethical framework 'accountability for reasonableness', priority setting in a hospital in Chile.

In policy making contexts that have historically been dominated by central authority, especially where there are limited resources, fair priority setting processes can empower people, foster social learning, improve the quality of the decisions, enhance compliance with policy decisions, and increase public confidence in the hospital.
\end{abstract}

Key words: priority setting, centralization, health care, accountability for reasonableness, culture

\section{ESTABLECIMIENTO DE PRIORIDADES EN UN SISTEMA DE SALUD MIXTO PÚBLICO/ PRIVADO: ESTUDIO DE CASO EN UN HOSPITAL CHILENO}

Resumen: El propósito de este estudio fue describir, a través del uso de métodos cualitativos en un estudio de caso, y evaluar, siguiendo la estructura ética de "Administración Razonable", el proceso de priorización en salud en un hospital de Chile. En el contexto de las políticas públicas ha dominado históricamente la centralización de la autoridad, especialmente cuando los recursos son limitados. Un proceso justo de priorización en salud puede empoderar a las personas, mejorar y aumentar el proceso de aprendizaje social, mejorar la calidad de las decisiones, aumentar el grado de adherencia y satisfacción de las políticas desarrolladas y aumentar la confianza pública en el hospital.

Palabras clave: priorización, centralización, sistema de salud, Administración Razonable, cultura

\section{ESTABELECIMENTO DE PRIORIDADES EM UM SISTEMA DE SAÚDE MISTO PÚBLICO/ PRIVADO: ESTUDO DE CASO EM HOSPITAL CHILENO}

Resumo: O propósito deste estudo foi descrever, por métodos qualitativos em um estudo de caso, e avaliar, seguindo a estrutura ética de "administração razoável”, o processo de priorização em saúde em um hospital chileno.

No contexto das políticas públicas onde tem dominado historicamente a centralização da autoridade, especialmente quando os recursos são limitados, um processo justo de priorização em saúde pode empoderar as pessoas, melhorar e aumentar o processo de aprendizagem social, melhorar a qualidade das decisóes, aumentar o grau de aderência e satisfação das políticas desenvolvidas e a confiança pública no hospital.

Palavras-chave: priorização, centralização, sistema de saúde, distribuição responsável, cultura.

\footnotetext{
Katholieke Universiteit Leuven, Centro Interdisciplinario de Estudios en Bioética (CIEB), Universidad de Chile, Chile Correspondence: valdebenito.carolina@gmail.com

** University of Toronto, Faculty of Medicine, Joint Centre for Bioethics, Canada

*** Department of Health Policy, Management and Evaluation, and the Joint Centre for Bioethics, University of Toronto, Canada
} 


\section{Introduction}

In December 2007, the Santiago Times (Santiago, Chile) reported: " 71 percent of the public hospitals and 40 percent of private medical institutes in Santiago did not adequately inform patients about the guarantees provided by the AUGE state health care plan... The health ministry estimated that more than 300,000 health care cases had gone unattended for lack of information since AUGE was initiated in 2005. Despite this high number, only 5,557 claims had been filed against hospitals, because the majority of patients did not know their rights were being violated". The health care plan, which began in 2005, covers 56 diseases, especially those occurring with greatest frequency in poorer communities, but "has still not met expectations".

Health plans in every country, whether rich or poor, primarily privately or publicly funded, cannot afford to pay for every service it may wish to provide. Consequently, difficult priority setting decisions must be made, what is crucial to meeting "expectations".

Priority setting, the distribution of resources between competing needs occurs in institutions at all levels of every health system, including: governments, forprofit and not-for-profit health insurers, hospitals, and clinical programs(1). Because it directly determines the sustainability of health systems, and because it affects patients' access to needed health services, it is arguably today's most important health policy issue(2).

While there's a growing body of literature on priority setting in health institutions, to our knowledge, there is no literature that describes actual priority setting in a mixed public and privately funded health care system, such as the Chilean Health Care System.

\section{Context in Chile}

Chile has a mixed publicly and privately financed health care system. However, the ministry of health (MINSAL) through the Superintendent of Health Care is responsible for the regulation and supervision of all healthcare policies. FONASA -the National Health Fund- funds the health sector through the National Health Insurance. FONASA was created to manage public sector resources generated through compulsory deductions from workers' salaries, central government contributions and income from user charges. The National Health Insurance serves about $68 \%$ of the population, predominantly the unemployed and/or those in extreme poverty(3).

Eighteen private insurance institutions (ISAPRES) provide healthcare funds to $18 \%$ of the population who make contributions through payroll deductions and monthly premiums which vary according to the specific coverage plan chosen by the client. Each ISAPRES specifies its own charges which vary according to the medical services covered, and their plans differ in coverage, providers and price, and the fees are in accordance to the patients' level of risk. ISAPRES favours people who are unlikely to fall sick -- that is, those who are rich, young and healthy who receive services through private ambulatory centers and hospitals(4). Inevitably, these different modes of health care financing introduced differences in access to health care services and, consequently, inequities.

To address these inequities the government of Chile, through MINSAL, developed health reforms with the principles of right to health care, equity in health care, solidarity, efficiency and social participation, and goals of reducing inequities face challenges of ageing population and provide services responding to public expectations. These reforms were presented to parliament, which approved five main laws including a system of explicit guarantees in predefined health conditions.

AUGE/GES is the Universal Access of explicit guaranties in health care, but it was changed to Guaranties Explicit on Health Care. This is a package of measures which expects to improve the quality of heath care for the people. However, it also places pressures on hospitals to meet population health needs and maintain quality within constrained budgets.

How have these reforms and modes of health care financing influenced priority setting at the hospital level?

The purpose of this study was to describe and evaluate priority setting in a hospital in Chile, a context with a private and public mixed financing system in a period of reform.

\section{Methods}

Design: We conducted a qualitative case study of priority setting in a Chilean hospital. A case study is "an empirical inquiry that investigates a contemporary phenomenon within its real-life context" (5). This is the 
appropriate method because priority setting in healthcare institutions is complex, context-dependent and involves social processes. Case studies are a structured yet flexible approach to data collection and analysis that has historically been used to describe institutions and their actions.

Settings: The study was carried out in 600 bed referral and University teaching hospital in Chile. The hospital receives funds from private systems but also a partial support from the University of Chile, which is a Public Institution. Thus, it is an academic hospital for the medical school. The hospital has a large patient population. For example, in 2006 the hospital received a total of 1,365,002 patients. The hospital estimated budget for 2007 was: USD \$ 116.2 million.

Sampling: We used a combination of snowball and theoretical sampling. Our interview sample included: administrators, physician-administrators, nurses and clerical assistants, and front-line physicians. Interview sampling continued until we achieved theoretical saturation-that is, no new themes emerged from successive interviews. We interviewed a total of 15 respondents (see Table 1).

Interview participants were contacted through telephone or email. Those who agreed to participate were subsequently contacted to set up a convenient time and place for the interview. Individual consent was obtained before each interview.

Data Collection: Data collection involved key informant interviews and documents review. We hoped to observe some meetings but discovered that budget meetings were held in private.

Interview data were collected using a semi-structured questionnaire. The questions were derived from the four conditions of the conceptual framework, A4R. The main themes covered included: Who makes priority setting decisions in the Hospital? Which are the main considerations? How are decisions disseminated? What happens if someone disagrees with a decision? In addition, the interviewer pursued concepts as they emerged during the interviews. We conducted 15 interviews with key informants.

The second source of data was documents. Most of the documents were obtained from MINSAL and the Pan
American Health Organization, but also from books and papers about the Chilean health system.

Data Analysis: Data analysis involved: Open coding -data were read, fractured into chunks that related to a concept or an idea, Axial coding- related concepts were organized into themes that were derived from the data and Selective coding -themes were developed and illustrated through verbatim quotes from the data.

The validity of the interpretations was enhanced in three ways. First, the research team facilitated 'reflexivity' (ensuring that prior assumptions, experience and personal bias were acknowledged and examined to ensure, as much as possible, the data analysis 'bends back on itself') and check preconceived assumptions. Second, a record of the data analysis and methodology were documented by the researchers to allow for a critical appraisal of the methodology. Third, the documents validated our findings from the interviews and also provided information on the context, including the national policies within which priority setting in the teaching hospital occurs.

\section{Conceptual framework}

'Accountability for Reasonableness'(A4R) is a conceptual framework for fair priority setting(6). It is theoretically grounded in justice theories emphasizing democratic deliberation $(7,8)$; it was developed in the context of real-world priority setting processes(9), and is therefore able to give practical guidance to decision makers. It has been used to evaluate priority setting in hospital in both wealthy and poor health systems(10-13). According to 'accountability for reasonableness', a fair priority setting process meets four conditions: relevance, publicity, appeals, and enforcement (See Text Box 1).

Research Ethics: The study received research ethics approval from the hospital in Chile. All respondents signed a consent form before the interviews and their confidentiality was secured throughout the study. All quotes are anonymous.

\section{Results}

In this section, we will provide the description and evaluation of priority setting at the hospital we studied. In addition, we have included verbatim quotes from study participants to help illustrate selected points. 


\section{Part I. Description of hospital priority setting}

\section{Processes}

According to some of our respondents at the meso-level, most of the key decisions are made at the macro-level. Priorities are developed by MINSAL and submitted to the national Congress -they deliberate, and jointly decide what services should be given priority. These decisions are received by the health care institutions as law to be applied in each institution. However, since there are significant budget differences between the health care institutions, and some do not have the resources to care for all patients, often they must be steered to other health care centers. Consequently, our respondents felt that the hospital managers merely applied what was decided at the macro level, though there was a small amount of discretionary spending to allocate.

Within the hospital, the priority setting process was reported to be led by the Hospital's General Director's office and involved frontline practitioners. As expressed by one respondent.

... All individuals working in this health service are involved: physicians, midwives, nurses, etc. Priority setting processes go beyond the involvement of professionals and of the leadership. I write the final report on priorities (administrator).

However, respondents who were not involved in the process reported otherwise. These felt that their specific departments were not involved in the process and hence, they lacked knowledge of the priority setting process. Others, mainly part time professional health care workers, said they were not involved at all, they just followed instructions. Hence these doubted the presence of any clear priority setting process within the hospital, as demonstrated by the quotes below;

I don't know clearly this process, the tools of PS are not very clear, I'm sorry I don't know (Physician)

In Chile there are no resources associated to the providers... the hospital doesn't have resources to allocate, in the hospital we just receive patients... (Nurse)

\section{Main considerations}

According to our respondents, since the hospital was financed by both public and private insurance systems, hospital managers must consider the guidelines and priorities established by both systems. For example, some respondents defined priority setting as the selection of the diseases established by the Ministry of Health through public insurance, MINSAL and ISAPRES. As an illustration, according to the AUGE/GES guidelines, the hospital cannot provide care for child cancer and extended burns services since they are not mandated by AUGE/GES. Several identified the role of the ministry as influencing their decision making. These reported a vertical process whereby the hospital decisions are influenced by the health care reforms, and they apply priorities identified by the Ministry of Health -- with no understanding of the rationales.

Within the hospital some respondents reported that their decisions are also influenced by the available resources. For instance, if the AUGE/GES mandates that each health care institution center must provide services for the 56 diseases identified (to date), the financial capacity of each institution will also shape what can be done. They also reported to be influenced by epidemiological information regarding the magnitude of the problem, social preferences called goals or targets for health care in Chile, which were determined through a national survey (This study is ongoing to improve that criteria.), treatment costs, and the effectiveness of the treatment for patients. (The main considerations are described in Table 3.) A few respondents thought that decisions were mainly based on economic reasons, while others thought that the most important consideration was the capacity of the hospital to respond to the patients' demands and needs.

As expressed below:

The implementation of the PS procedures has been decreed and ordered in a vertical, absolute way by the health reform stemming from the AUGE/ GES. This implies an imposed agenda that defines production processes, health care administration, and services provided.

We have limited resources; this is a real, concrete problem. Thus, we establish priorities along with the hospital's Directorate according, not only to the AUGE guidelines, but also to the available resources and the health needs of the public. (Administrator) 


\section{Dissemination of the decisions and reasons}

According to our respondents, macro-level decisions related to health care goals and targets have been shared with the public since 2000. The goals and targets are established through surveys carried out by MINSAL, and are disseminated on the MINSAL website. Also, MINSAL disseminates the information through SEREMIS, the Secretary of Health Care for each region, who provide these goals and targets to each health care institution. The Ministry, MINSAL, the ISAPRES and the hospitals, as constituents of the network of AUGE/ GES health care reform, are to provide patients with free information with regards to the participating providers and services. Furthermore when a patient is diagnosed with some prioritized disease, the patient is automatically referred to his/her health care insurance in order to obtain the free cost for care. In addition, the network of AUGE/GES should inform each physician about the pathologies that are covered by it They also inform the patients about the participating physicians and health facilities where patients can access to free medical treatment. This information is communicated through internet and mass media and in each center of health care. However, as they rely on mass media, they have no assurance that the message is received by patients.

Health care providers are also supposed to provide information and guidance to their individual patients. However, some respondents doubted the availability of this information to the patients since the providers were thought to give information only to patients that ask for it, and most of the patients commonly don't.

\section{Knowledge of the priority setting process}

There were three levels of knowledge of the priority setting process, which were dependent on the respondents' involvement in the process: (i) Those with a good level of understanding of the priority setting process were those most intimately involved, mainly the hospital managers and administrators; (ii) Those who could only describe a few aspects of the process were typically health professionals who worked in the hospital on a part time basis and had heard about the process second-hand; and (iii) Those who confessed total lack of knowledge of the process and were not aware of any priority setting process within the hospital.

\section{In case of disagreement}

Respondents who described a centralized decision making process felt it was difficult to disagree with or even appeal a decision that had already been made at the macro-level -- there was no formal mechanism for challenging decisions. They also reported that it was difficult to disagree with decisions made within the hospital: the lack of anonymity at the meso- and micro- levels makes it less likely for people to openly disagree. Some participants blamed this on the history of authoritarian governance in Chile, which was characterized by repression and censorship and no opportunity to disagree with government decisions

The AUGE/GES, reform defines the way to work inside the institutions, and the funding, and it is not possible to refuse their decisions. (Nurse)

Some respondents felt it was possible to disagree with the decisions even at the macro- level. They reported that they were able to 'negotiate' with MINSAL, since they knew the capacity of the hospital to meet patient needs and were hence more equipped to inform the decision makers what was and was not feasible within the hospital.

\section{Part II. Evaluation of the description against Ac- countability for Reasonableness}

\section{Relevance}

Most of the hospital-level decisions were determined by the MINSAL and ISAPRES, and the hospital adapted these priorities according to the resources they received and their own capacity. As such, priority setting primarily involves administrators at the MINSAL and were based on the guidelines proposed by the MINSAL (national goals and targets), the available resources, and the hospital's capacity to respond to patients' demands, epidemiological data, costs and effectiveness of the interventions. However, there was not widespread stakeholder engagement, the public was only involved through the national surveys. The relevance condition was only partly met.

\section{Publicity}

Decisions made at the national level were disseminated through mass media and internet. It was not clear whether similar mechanisms were available and/or functioning within the hospital. The hospital expected 
practitioners to communicate this to their patients. Although it was possible that patients and members of the public could hear about the hospital priorities, they often did not. The publicity condition was only partly met.

\section{Revisions}

There was no formal mechanism for revision or appeals. Some respondents involved in the process thought it was possible to appeal decisions informally. Others felt it was difficult for some people to express their dissension due to lack of access to decision makers and governmental culture that historically has discouraged disagreement. The revisions/appeals condition was not met.

\section{Enforcement}

There was no explicit activity on the part of leaders aimed at ensuring adherence to the conditions of fair priority setting. Moreover, there was no mechanism for evaluating and improving the process. The enforcement condition was not met.

These findings point to clear improvement strategies, which will be detailed below.

\section{Discussion}

To the best of our knowledge, this is the first study that describes and evaluates priority setting in a hospital in a mixed private/public health system, in our case Chile.

This context presented challenges for hospital priority setting research because of the multiple funding sources and multiple context-specific criteria that contributed to set hospital priorities. In particular, it is difficult to achieve fair priority setting because there isn't any process that may be targeted for improvement strategies.

We found that there are efforts to make priority setting fair in this context: The process involved a wide variety of stakeholders and was based on explicit reasons that some of the respondents thought were relevant. The national government provided information for patients about access to health units that offer covered services. The national health fund, FONASA, and the private insurance institutions, ISAPRES, also provide information on the services they cover. While these contribute to the process being fair, there is room for improvement.
In many cases hospital priority setting is constrained by directions from the Ministry of Health. However, there is always discretionary spending in hospitals, even if it is a relatively small percentage of the budget.

With regard to stakeholders, there was a group of respondents, mainly those who work on a part time basis within the hospital and those who do not hold managerial positions, who reported that they were left out of the decision making process and lacked knowledge of the process. Interestingly, most of them associated priority setting with the health reforms (AUGES/GES), which have been well publicized by the MINSAL ${ }^{1}$. These findings are similar to previous studies where frontline practitioners were reported to lack access to the decision making process(12). Since frontline practitioners contribute to the running of the hospital, they are important stakeholders that should be involved in their hospital's priority setting.

We found out that the interventions covered by FONASA and ISAPRES were publicized. However, there is evidence that patients and members of the public were not necessarily receiving that information. In addition, there were no clear mechanisms for dissemination of decisions made within the hospital. The coverage information was reportedly available to only those patients who asked for it. To ensure equitable access to information, the leaders at the macro- and meso-level and providers at the micro-level should be more pro-active in providing information. Moreover, as has been found elsewhere, the decisions, but not the rationales are publicized (14) -there is need to endeavor to publicize the rationales as well.

Macro level priority setting comes closest to fulfilling the conditions of A4R, but there is room for improving the fairness of priority setting at the meso and micro level.

Some investigation may be required to determine why the current communication strategy is less than optimally effective, and to develop a more effective communication.

This context lacked a clear appeals mechanism. Most health institutions in both high and low income countries lack appeals mechanisms. Consequently, people use informal mechanisms to get what they want (e.g. back door lobbying), which introduces un-

1 Ley 19966 de 2004 o Ley AUGE (Acceso Universal con Garantías Explícitas). 
fairness (12,15). Even within resource-poor contexts, there should be mechanisms where dissensions can be presented and discussed. If counter-arguments are rejected by decision makers, the reasons for the rejection should be publicized. In cases where resource reallocation (a very contentious issue) may be the only solution, transparency and consistency would facilitate compliance and enhance trust.

Some of our findings can be explained partly through understanding the economic context of low and middle income countries. However, in addition, the historical and political context within which priority setting in this particular hospital occurs may explain some of our findings.

Most of the countries in Latin America, Chile inclusive, have had a military dictatorship government $(16,17)$. This socio-political phenomenon is important when considering the principles of a fair process and may explain why decisions were reported to be centralized whereby hospitals managers perceived themselves as just implementers and not participants in the effective decision making process. The history dictatorial governance was also given as a possible reason for people not appealing -where there is no anonymity (as within the hospital), people fear to disagree with decisions.

Furthermore, the colonial history whereby people were taught to submit to authority, and the hierarchical power-structures instituted in previous centuries by the Spaniards, may also explain why it may be difficult to develop legitimate and fair priority setting processes - even with recent efforts to introduce a democratic government and to have people participate in decision making. This cultural matrix, which characterizes most of Latin America, turns it difficult to integrate deliberative decision making since people do not feel entitled or empowered to play this role in decision making.

In societies where people feel disempowered there are advantages for ensuring fair policy making processes. Fair deliberative processes facilitate social learning about the need to set limits in health care, reduce dissensions in the long run, and promote satisfaction and trust in the health institutions and health system at large. Moreover, increases in democratic participation have also been associated with positive socio-economic development in low and middle-income countries ${ }^{2}$.

2 World Bank, Development Outreach, November 2007. http://www1. worldbank.org/devoutreach/index.asp)
Ultimately, leaders within each priority setting context are responsible for ensuring that the conditions of fairness are met. Previous research has determined that, even in wealthy countries where democratic policy making is more accepted historically, ethical leadership is the single most important element of fair priority setting, and the condition where there is the most room for improvement $(11,18)$.

\section{Possible improvements}

To improve the fairness of priority setting within the hospital, its management should:

1. Ensure effective participation of especially the frontline practitioners - who felt excluded from the decision making processes. General staff meetings may facilitate this process.

2. Ensure more public involvement in the decision making process. While they are represented through the board of directors, the public should be made aware of the decisions made within the hospital by the management publicizing both the decisions and rationales to the general public through yearly public assemblies and the media.

3. Identify and explicitly document and publicize the reasons behind the resource allocation decisions through effective accessible modes such as meetings, the media and internet.

4. Establish clear mechanisms for appealing resource allocation decisions. The existing hospital management team may provide that service, in addition to their roles. This mechanism should be publicized and used consistently and effectively to prevent informal appeals.

5. Hospital management should also assume leadership to ensure that all resource allocation decisions made within the hospital involve all relevant stakeholders, are based on relevant rationales, publicize both decisions and reasons behind them and provide mechanisms for appealing decisions. This may involve an ongoing iterative approach to quality improvement in priority setting(19).

\section{Conclusion}

Where there are limited resources, fair priority setting processes can empower people, foster social learning, improve the quality of the decisions, enhance compliance with policy decisions, and increase public confidence in the hospital. 
Hospital priority setting in a mixed public/private health system - Carolina Valdebenito, Lydia Kapiriri, Douglas K. Martin

\section{Acknowledgements}

We are grateful to all participants and for the assistance provided by the Academic department of the Hospital University of Chile thanks to its secretary.

Table 1. Overview of Interview Participants

\begin{tabular}{|l|l|}
\hline Interview Participants & \\
\hline Number Respondents & 15 \\
\hline Females & 8 \\
\hline Males & 7 \\
\hline Administrators/ & $\begin{array}{l}9 \text { persons with administrative and } \\
\text { directive position: } \\
\text { 6 persons without administrative } \\
\text { position }\end{array}$ \\
\hline
\end{tabular}

Text Box 1 - The four conditions of Accountability for Reasonbleness

\begin{tabular}{|l|l|}
\hline Relevance & $\begin{array}{l}\text { Rationales for priority setting decisions must } \\
\text { rest on reasons that stakholders can agree are } \\
\text { relevant to the context. }\end{array}$ \\
\hline Publicity & $\begin{array}{l}\text { Priority setting decisions and their rationales } \\
\text { must be publicity accessible. }\end{array}$ \\
\hline $\begin{array}{l}\text { Revisions/ } \\
\text { appeals }\end{array}$ & $\begin{array}{l}\text { There must be a mechanism for challenge, } \\
\text { including the opportunity for revising decisions } \\
\text { in light of new information or arguments that } \\
\text { stakeholders may raise. }\end{array}$ \\
\hline Enforcement & $\begin{array}{l}\text { Leaders in the priority setting context are } \\
\text { responsible for ensuring that the first three } \\
\text { conditions are met. }\end{array}$ \\
\hline
\end{tabular}

Table 2. Main considerations in hospital priority setting in Chile

\begin{tabular}{|l|l|}
\hline Consideration for prioritization process in Chile \\
\hline Financial capacity & $\begin{array}{l}\text { the health care centers must have the capacity to respond to the social demands as well as the MINSAL } \\
\text { requirements }\end{array}$ \\
\hline Epidemiology & $\begin{array}{l}\text { To date, at least } 56 \text { diseases are covered, and the Government of Chile and the MINSAL are engaged to include 80 } \\
\text { pathologies for the year 2010. }\end{array}$ \\
\hline Social demands & $\begin{array}{l}\text { Equality, dignity, universal access to health care. But, access is determined by the system of insurance which each } \\
\text { patient has. According to the Superintendent of health care in Chile, the social determinants regarding health care } \\
\text { are associated too with social and cultural changes } \\
\text { Therefore, the most important social demand in health care in Chile currently is to improve the quality of life and } \\
\text { reduce deaths due to life-style. }\end{array}$ \\
\hline $\begin{array}{l}\text { Health care goals } \\
\text { and targets }\end{array}$ & $\begin{array}{l}\text { That goals and targets of health care were obtained through national survey which is deliberated by the MINSAL. } \\
\text { Currently there are goals till 2010. The main goals and targets are: to improve the goals reached so far, to face the } \\
\text { new challenges as product of the population's aging, to reduce the inequalities on health care, and to provide the } \\
\text { heath care services according to social demands. } \\
\text { The goals of the health care reform AUGE/GES are: to integrate private and public sectors; to define the explicit } \\
\text { guaranties to the citizenships; to improve the health care services and the management on the health care resources; } \\
\text { to enhance solidarity; and to regulate the real implementation of the AUGE/GES. }\end{array}$ \\
\hline
\end{tabular}

\section{References}

1. Ham C, Coulter A. International experience of rationing (or priority setting). In: Coulter A, Ham C, (eds.) The Global Challenge of Health Care Rationing. Philadelphia: Open University Press; 2000: 1-12.

2. Martin DK. Making Hard Choices. The Key to Health System Sustainability. Practical Bioethics 2007; 3(1): 1-8.

3. Caviedes R. Pandora Médica. Medicina, Poder y Dinero. Santiago de Chile: CIEDESS; 2004.

4. Lenz R. Políticas públicas en salud: experiencias y desafíos 1990-2010. En Meller P, (ed.) La paradoja aparente. Equidad y eficiencia: resolviendo el dilema. Santiago de Chile: Taurus; 2005.

5. Yin RK. Case Study Research: Design and Methods. Thousand Oaks, CA: Sage Publications, Inc.; 1994.

6. Daniels N, Sabin JE. Setting Limits Fairly: Can we learn to share medical resources? Oxford, UK: Oxford University Press; 2002.

7. Cohen J. Pluralism and Proceduralism. Chicago-Kent Law Review 1994; 69: 589-618.

1 "Establecimiento de Prioridades y Reforma de Salud en Chile". Presentación de Manuel Inostroza Palma, Superintendente de Salud de Chile, enero de 2007. 
8. Rawls J. Political Liberalism. New York: Columbia University Press; 1993.

9. Daniels N, Sabin JE. Limits to health care: Fair procedures, democratic deliberation and the legitimacy problem for Insurers. Philosophy and Public Affairs 1997; 26(4): 303-502.

10. Martin DK, Shulman K, Santiago-Sorrell P, Singer PA. Priority Setting and Hospital Strategic Planning: A Qualitative Case Study. Journal of Health Services Research \& Policy 2003; 8: 197-201.

11. Releeder D, Martin DK, Keresztes C, Singer PA. What do hospital decision-makers in Ontario, Canada have to say about the fairness of priority setting in their institution? BMC Health Services Research 2005; 5:8.

12. Kapiriri L, Martin DK. Priority Setting in Developing Countries Health Care Institutions: The case of a Ugandan Hospital. BMC Central Health Services Research 2006, 6: 127.

13. Ham C, Roberts G, (eds.) Reasonable Rationing: International Experience of Priority Setting in Health Care. Maidenhead, UK: Open University Press; 2003.

14. Mielke J, Martin DK, Singer PA. Priority Setting in Critical Care: a Qualitative Case Study. Critical Care Medicine 2003; 31: 2764-2768.

15. Madden S, Martin DK, Downey S, Singer PA. Hospital Priority Setting with an Appeals Process: A qualitative case study and evaluation. Health Policy 2005; 73: 10-20.

16. Valdebenito C, Lolas F. Ética de la gestión en salud: un dilema sociocultural. Cuadernos de Bioética 2004; 15(54).

17. Valdebenito C. Relaciones médico-pacientes: Construcción axiográfica del poder. Tesis Magíster en Salud Pública, Santiago de Chile: Universidad de Chile; 2007.

18. Reeleder D, Goel V, Singer PA, Martin DK. Leadership and Priority Setting: The perspective of hospital CEOs. Health Policy 2006; 79: 24-34.

19. Martin DK, Singer PA. A Strategy to Improve Priority Setting in Health Care Institutions. Health Care Analysis 2003; 11(1): 59-68.

Recibido: 14 de julio de 2008

Aceptado: 18 de noviembre de 2008 